\title{
Reading underused urban spaces: Aberdeen views.
}

\author{
ZECCA, C. and LAING, R.
}

2020 


\section{Reading underused urban spaces: Aberdeen views}

\section{Cecilia Zecca and Richard Laing}

Postal address: $\quad$ The Scott Sutherland School of Architecture \& Built Environment Robert Gordon University

Sir Ian Wood Building, Riverside East

Garthdee Road

Aberdeen

AB10 7GJ

UK 


\begin{abstract}
This paper explores the application of a combination of urban analysis methods in order to gather data and explore the implications of abandonment in a city. Nowadays, in a period of economic recession, developments based on demolitions and reconstructions, are not always suitable. The direction of this paper includes the idea of existing areas, buildings and their reuse as a main and primary starting point of the built environment sustainability. The research uses Aberdeen, Scotland, as a case study. Within the research, the concept of urban abandonment is explored across three subcategories, which enable the clarification of differences between various urban conditions and features.
\end{abstract}

The aim of the paper is to demonstrate that a certain combination of qualitative methods can enable a detailed exploration of the current urban situation. This detailed information enabled to gather more empirical quantitative data based on the consideration raised from the analysis. The work is original in that it seeks to combine theories of abandonment with the spatial assessment of urban environments, and thus holds the potential to carry significance within urban design and planning practice.

Keywords: urban, abandoned, reuse, spatial, design 


\section{Introduction}

The specific context of this paper involves an investigation of the contemporary phenomena of obsolescence at both urban and building scale as a result of ongoing city expansion over the last forty years. The evolution of contemporary urbanity, thus, must face what may be the remains of the extensive construction of the modern period in architecture.

It can be argued that horizontal European city growth is no longer sustainable, neither in terms of cost, recycling (construction side, gas or electricity supply, general and urban waste, infrastructures, etc.) nor in terms of space. In this sense, it appears relevant to measure and value the level of obsolescence within the city to master the related issues and to facilitate the re-use of those spaces towards a more sustainable urban evolution.

A key term is the concept of abandonment. It is used to describe the generic urban spaces and buildings that belong to the category of the places used in the analysis. Abandoned spaces often represent an image of historical architectural ruins related to military, industrial or political remains. However, more recent urban research (Corsaro 2010) adopted this term to outline neglected areas within the urban landscape as a result of the ongoing city expansion over the last forty years. The value of such buildings and spaces, especially where they embody important cultural and social value, has been recognised and should form part of the strategy to revitalise urban areas (as described in Misırlısoy and Günçe, 2016).

From an intellectual perspective, this paper represents an original contribution to the study of abandoned and ill-defined (non-) spaces in urban areas. In particular, the general concept of abandonment is unpacked in subcategories useful to individuate the features of different urban areas and environment. This helps to clarify their urban nature, their role or absence within the city context and to better understand the related implications of regeneration projects. 
This phenomenon of abandonment has led to the development of various typologies for residual and neglected spaces. These include: urban voids; old industrial unused settlements; obsolete infrastructures; which have become new icons of the contemporary urban scenario (Cariello, A., Ferorelli, R., 2014).

Using the adjective abandoned however, is arguably too generic and the risk may be that this term is used more from habit than to refer to specific characteristics of particular spaces. The study of these relatively new residual spaces around the city has been underpinned in various disciplines. To define a general conceptual and analytical frame of the contemporary urban realities in the last thirty to forty years, three subcategories of abandonment have been selected. In this regard, the paper contextualises the urban phenomena of abandoned spaces through the conceptualizations of non-places, empty places and fragmented urban voids.

These three subcategories were selected in relation to the context of Aberdeen city. In particular, non-places are individuated as impersonal spaces characterised by hyperfunctionalism or a lack of localism which create sterile places for human interactions; empty places are individuated as unused and inhabited buildings; fragmented urban voids are individuated as dividing spaces which do not have any active role or use within the city.

The three subcategories enabled to understand the differences between abandoned and underused spaces in Aberdeen and helped to categories them within a taxonomy which illustrates the problematics related to the areas.

\section{Rational of the selected subcategories of abandoned spaces}

The classification of existing abandoned spaces is based on particular differences encountered during urban analysis and observation of cities. Particularly, the originality of the study relies on exploiting theoretical notions normally explored within social and anthropological studies, 
but here applied within an architectural setting. A contemporary urban difficulty concerns a lack of relations between spaces and a lack of application with regards to reuse planning and regeneration, rather than current abandonment and urban expansion. Lack of identity leads to the idea of void or even specifically to the notion of nothing. Ritzer, (2004) argued that the culturally controlled social forms are lacking in content. This is especially the case of the new social spaces defined non-place by Auge' (1995) such as shopping malls. In this sense, each theoretical category has been brought within the more technical discipline of urban study and rationalised in order to recognise it and make it quantifiable. The following explanations critically reconsider the only theoretical notion of non-place, empty place and fragmented void, contributing to urban and architectural studies. All notions are interrelating to each other by the lack of various urban relations with the other parts of the city and between the users, so a lack of physical, social and urban functions.

Non-place: The notion is not just related to functional spaces, such us train station or airport, but to all spaces not thought for social activity and as a possible destination within the city. A city with a high ratio of non-places in comparison with its places is then not a city liveable at a human scale. In this regard, establishing and naming a subcategory of non-places may be strategic to define what should be maximized and what should be minimized in view of an urban regeneration design. Examples are traffic roads, green spaces not used, wide squares used as car park.

Empty place: The notion is related to the concept of emptying a container. An abandoned building is therefore categorised as empty place because of its possibility to be re-converted as social and more public place. The main phenomenon of emptiness in terms of urban consequence, is related to the generation of urban borders. The lines between outside and inside are more strongly marked and defined once the building becomes abandoned. Paradoxically 
the emptiness of a building raises and reinforces the presence of the past and thus the history of a place.

Urban fragmented void: is the opposite of solid, so an unconstructed space with no particular significance. It is generally unpleasant and the result of unconsidered space between two constructed areas. The direct consequences are sense of degradation, disconnection with the rest of the city and incompleteness.

\section{Methodology}

For this research, the main methods used for analysing the areas drew on established urban theory and previous research. Thus, the city of Aberdeen and selected case study site(s) have been read and understood through a wide spectrum of observation methods and described later in this paragraph.

To obtain pertinent urban data, graphic maps, photos and diagrams were used to understand the existing conditions of the areas and to classify them within different urban categories, particularly focused on different cases of abandonment. The choice of these methods of analysis was used accordingly to the characteristics and the nature of the areas, for instance a rhythm analysis has been used mostly to monitor the use of those spaces.

For the case study analysis reported in this paper, four methods have been selected according to their extensive and well referenced use for analysing the city.

\subsection{Mapping}

By mapping areas on a broader and macro view of the city context, the research was enabled to contextualise and understand the relations between different parts of the city. Areas (macro 
and micro) were highlighted on the map at a large scale, and their relations with the surrounding urban systems have been then explained graphically through a map of urban layers.

This initial layers-relation observation method was aimed at supporting the research to obtain a scheme of Aberdeen urban territory and a scheme of the areas characteristics in relation to the city. Areas were individuated under their morphological position (Barresi, A. Pultrone, G. 2009). The areas are also individuated on a second level of decomposition of the map and confrontation between each other.

Similarl to Emerson's (2014) approach for the abandoned industrial areas in Glasgow, isolating the areas on the map appears to be a useful method to clarify their dimensions and relations in terms of distances and visual connections.

\subsection{Typo-morphological analysis}

The purpose of using this method to collect data related to the areas selected in Aberdeen was to apply a particular lens to effectively identify the characteristics that define the identity both natural and constructed.

Every area has been analysed at an appropriate scale in order to read the form generated by solids and voids and the settlements stratification over different ages; the architectural typology of relevant buildings presented in the areas have been selected and extrapolated from the map to be analysed in their use and architectural features. In particular, the relations between pedestrian accesses and urban space have been highlighted on the maps in order to understand the urban accessibility weakness and potentialities. The main urban spines, if any, have been read in their twofold role of connection and separation between urban space and built environment. This method enabled the research to understand the relation between the 
evolution and the expansion of the city in terms of urban form and typology of the built environment.

The Rossian concept of permanence (1982) is particularly highlighted through typomorphological analysis as demonstrated historically, for instance, in the evolution of Lucca piazza dell'Anfiteatro where the medieval constructions are distributed around the remaining form of the ancient amphitheatre. In this regard, the urban morphology persists and establishes different relations with later interventions.

As Formato (2001) argued, urban morphology is a strong sign of identity for a city and the extent to which it can resist functional changes over the time. In this sense analysing both the urban form and the typological functions and features of the buildings helps to comprehend the genetic code of the city.

The word morphology has been utilised extensively to indicate a certain level of investigation delivered on an appropriate dimensional scale where the complexity of urban relations is higher than a single building investigation (Gregotti, V. 1966).

Since urban morphology can make use of a broad range of critical and practical instruments, it can play a valuable role here, as a disciplinary bridge between history and contemporary urban design.

(Maretto, M. 2013)

Saverio Muratori (1967) can be considered the pioneer of morphological urban studies. Morphological analysis does not have just the aim of recognising solely the current conditions of an urban space. On the contrary, the aim is to evidence the internal structure and all elements through a critical analysis of their potentialities intrinsic to their development process. By 
analysing Muratori urban projects, Maretto (2013) describes the development of Muratori's perception concerning the urban structure formative logic. Specifically, the author describes his concept of transition from bringing together theory and architecture to morphology analysis as planning discipline. In this regard, it is noticed that morphology analysis has been recently reconsidered as an important step for mastering complex urban projects (ibid), particularly for two main reason: on one hand the growth of contemporary cities and their population requires deep consideration of settlements forms and transformations' mechanism over time; on the other the necessity of developing more sustainable cities is directly connected with society and not just with energy consumption. In this sense, Maretto states that the form of existing cities and their use should be transformed according to daily life.

Morphology criterion of scale, both architectural and social, lends itself perfectly to drawing together the various operative levels of sustainable strategies, and indeed can contribute to launching a new urban culture for the twenty-first century.

(Maretto, M. 2013)

The typo-morphological analysis method aims to read the "DNA of the city" (Barresi, A. Pultrone, G. 2009) and is a resource for encompassing the transformations' possibilities. In this respect, this method may be considered as both an interpretation and a guide for urban development and transformation considering all levels of complexity within the urban forms and the architectural features.

\subsection{Rhythm analysis}

Rhythm defines a mode of experiencing spaces and places within the city with direct implication for the urban design. In this sense, observing how the areas are experienced by the users helps to encompass the sense of the places and their intrinsic uses. 
This method has been applied on selected areas through a map that highlights human flows and their intensity with the help of diagrams. The rhythmicity of the areas selected has been also analysed with photographs taken at different times of the day in order to study the frequency and the use of the spaces. These data are reported and graphically schematised within a taxonomy.

Urban spaces are geometrically different; generally, the linear ones, such as infrastructures, fit for a specific purpose which is moving from one point to another, while the aerial ones are inhabited more randomly. The main morphological and typological character of urban long element is the forced and directional flow of humans which differs completely from the flow of an aerial geometry such as a park.

Rhythm analysis as method for investigating urban spaces is an approach to analyse the relation between space, time and society. (Hetherington, K.; Smith, R. J. 2013)

The concept of rhythm is given by the repetition that regulates and reproduces the sense of urban space and its relational aspects of the place life. Lefebvre (2004) argues that rhythm analysis offers the possibility to understand the complexity of the spaces, their interactions, mobility and the connections between particular and universal.

The rhythm of inhabiting an open public space is completely different, for instance, to the rhythm of public transportation. In this sense this analysis enables to clarify the different relations between the factors of the equation spaces-dimension-speed-time-tempo.

In terms of graphical description, according to Mareggi (2017), representing the rhythm of urban space considering the activities and the intensity of frequentations would be more an interpretive approach against the more objectives. This seems however appropriate for this 
research because the interpretation of urban rhythmicity may suggest the potential of future design actions (ibid.).

Mareggi (2017) describes seven different types of temporality and variety of the urban environment, which can be represented in static or dynamic maps. Two of these seemed to be more appropriate for the context of Aberdeen. Particularly the areas selected have been analysed considering the opening time of the activities and the intensity of users' frequentation (ibid.) collected through a series of photo frames.

\subsection{Mental map}

Using interpretative diagrams to summarise the main urban feature of the areas enables to select and identify the urban environment within pattern. This concept derives firstly from the Gestalt theory (Sema Uzunoglu, S. 2011) which recognise common perceptive process related with various forms. In this regard, it is possible to understand which urban forms and characteristics of the areas are relevant for future design processes. The most recognisable and clearest parts of the city, thus, play important roles in terms of identity and they contribute to the drawing of the form of the city.

Although the original method adopted by Lynch (1960) was intended as graphic interview directed to citizens in order to study their perception processes of the city, in this research, the mental map is intended to produce graphical schemes, based on the previous analysis maps, sites observation and discussions raised through academic work delivered together with students and planners.

According to Lynch (ibid), mental maps are useful to clarify the common perceived elements of the city plan that are fundamental for defining a collective idea of the city. From the mental maps collected by the author emerged that some perceptive constants could be classified. 
Particularly, Lynch noted that linear infrastructures, such as railways but even beaches, were seen as barriers or edges; rather typical street, roads and occasional routes were classified as paths to localise other elements or monuments; the junctions and crossing points were identified as nodes; the homogenous areas were selected as typical districts; finally, relevant elements helpful for the orientation were defined landmarks.

It can be argued that Lynch introduced a new urban geography, different from the spatial traditional analysis of the city. His approach and method are, in a certain way, similar to the typo-morphological analysis based on the concept of plan, site-location, typology and historical evolution, with the difference that Lynch introduced the concept of environment perception and subjective liveability.

For each of the areas studied, the research employed these four methods (mapping, typomorphological analysis, rhythm analysis and mental mapping) in combination. This enabled the studies to capture the spatial configuration of the areas (typo-morphological), as well as information emerging from discussion with participants, and deep on-site observation, regarding perceived use of the spaces (rhythm and mental mapping).

\subsection{Classification and taxonomy of areas}

The aforementioned urban analysis methodology supported the study of Aberdeen areas and allowed the research to collect data in order to understand the issues and lack of urban and social relations of those spaces. In particular, by examining the data and by triangulating the information collected, it has been possible to categorise every area within particular subcategory of space belonging to the general notion of abandonment, such as empty-place, nonplace and fragmented void. To better support and reinforce the results obtained, a simple calculation has been used to quantify the level of abandonment in proportion to the entire area 
expressed in square metre. According with the common urban density/floor ratio (Dell'Aguzzo, M. 2013; Yu-Hsin, T. 2014), used to calculate the index of built areas or open spaces within a specific area considered and which is generally expressed with the formula factor to be determined/ total square metre of the area, the abandoned spaces within the areas selected in Aberdeen have been divided by the total square metre of the areas. In this sense, the taxonomy presents also the index of abandonment within every area which is also, logically no greater than 1 .

\section{Case study: Aberdeen}

The European economic recession sensibly affected Aberdeen city, which revealed its vulnerability related to an economy so heavily focused on the oil and gas sector. Notably, the 2015 masterplan guidelines reveal proposals for urban improvements based only on proposal led by developers from the private sector which may be arguably seen just as pragmatically orientated.

I am enough of an artist to draw freely upon my imagination. Imagination is more important than knowledge. For knowledge is limited, whereas imagination embraces the entire world, stimulating progress, giving birth to evolution

(Einstein, A. 1929. Originally in "What Life Means to Einstein"; Calaprice, A. 2000).

Approaching these urban scale problems requires a holistic effort from both intellectual and practical perspectives. Different knowledge and multidisciplinary studies on the current urban issues related to Aberdeen city could help to recognise other aspects and reconsider the possible solutions through a different lens overcoming the risk of lack of imagination.

The analysis aimed to investigate the city more holistically, interpreting the various aspects of it. By defining the potentialities of the spaces through the data and information shown on the 
drawing maps, these types of analysis-instruments enable to draw a detailed taxonomy methodologically structured.

\subsection{Mapping - relation with the urban context}

As a first phase in analysing the areas selected in Aberdeen, photographic aerial images from

Digimap were used to map and identify the areas within their surrounding urban context. In this respect a first visual interpretation, elaborated with graphic software by the author, has helped to identify their dimensions, physical forms and positions within the city. From this first view of the areas it appears clear that they are almost fractal urban spaces, thus are not just constructed solids but mainly spaces in-between the built elements. The diagram drawn on the map then, has been isolated to better understand the relation between the areas and also to visualise and evaluate the fragmentation and the proportions of the selected abandoned spaces within the city.

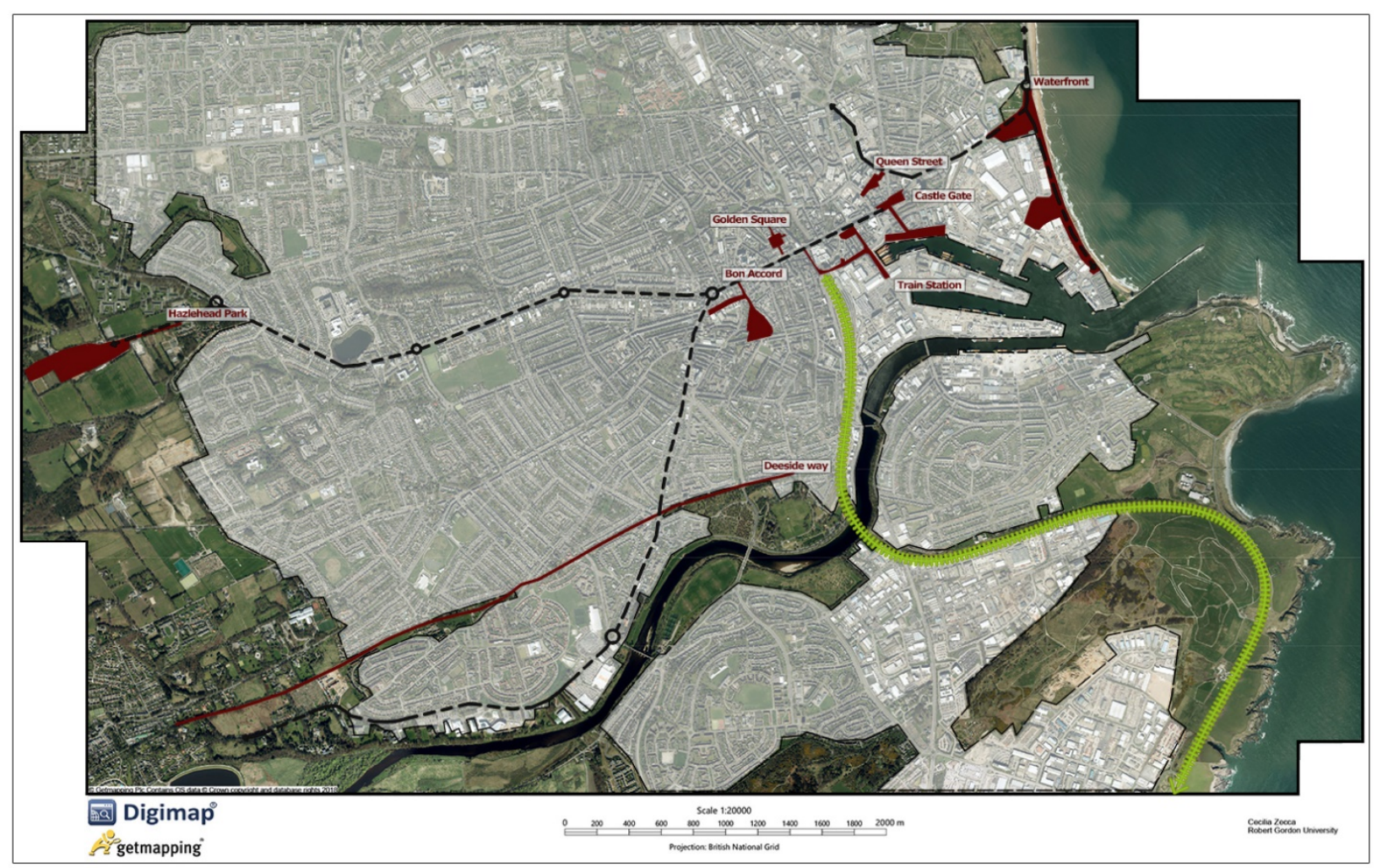

Fig.1: Aberdeen, map of abandoned areas on photogrammetric picture 


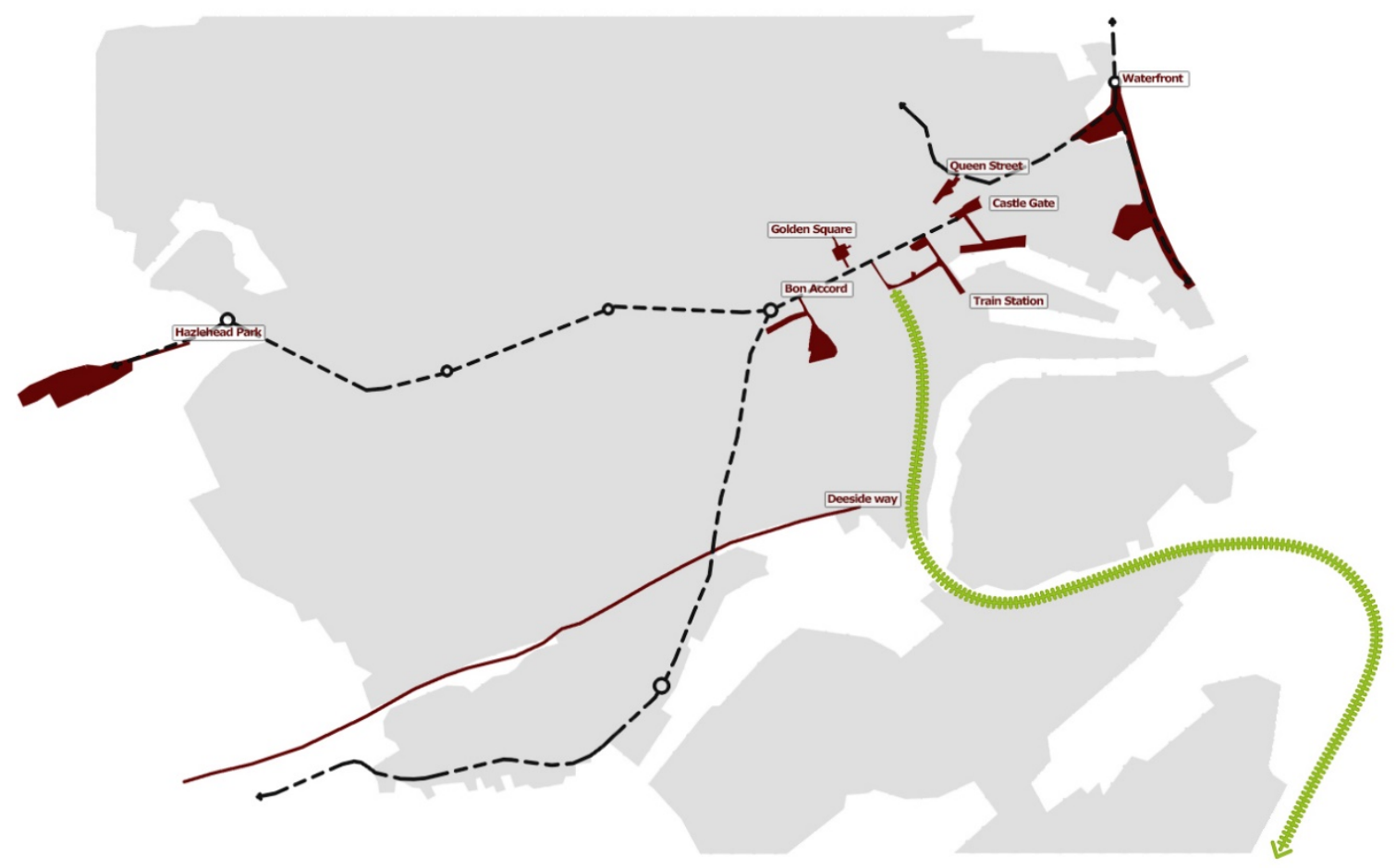

Fig.2: Aberdeen, representation map of abandoned areas

What emerged from these maps is a regular distribution of the areas along a spine, mainly Union Street and its continuations of Queen's Road and the Beach Boulevard.

From this scale the areas within the city centre seem closed to each other, suggesting a net of abandoned urban spaces, which could potentially become a widespread net of re-connections. 


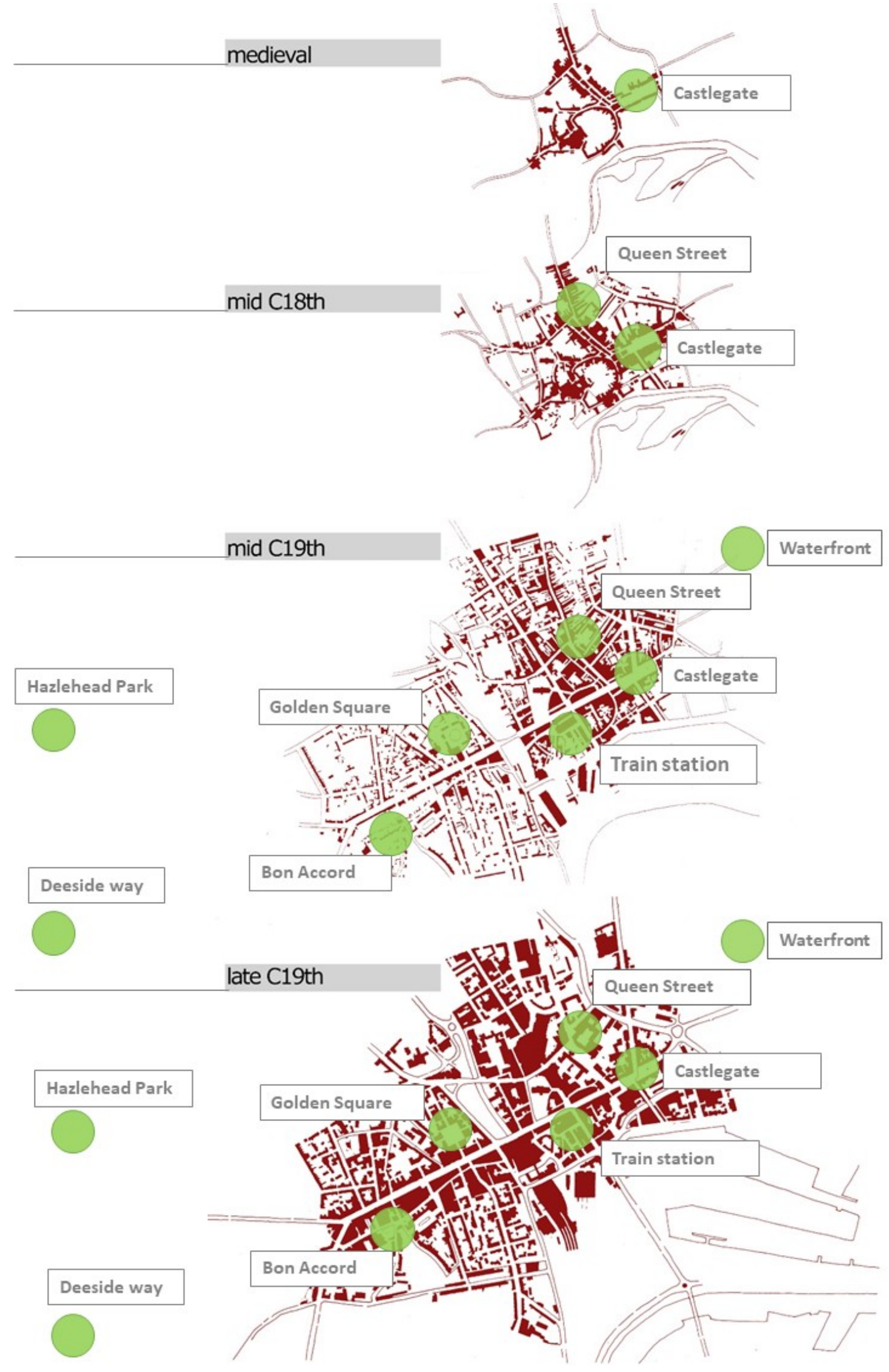

Fig.3: Aberdeen, historical evolutions 
The historical evolution of the city (fig. 3) suggests that in a first moment the growth followed a centripetal configuration around Castlegate and the Green. The later establishment of Union Street and the dense constructions along it, generated a spine of isolation between different parts of the city. If on the one hand Union Street is a west-east connection axis, which does not lead to the sea due to the orthographic conformation of the land, on the other it separates the south and north areas. The areas selected, with the exclusion of Castlegate and Queen Street, are situated in the most recent expansion of the city.

Subsequently, in order to have a clear understanding of the areas, each one has been analysed, on a bigger scale, and to identify the connections and relations with the surrounding built environment and the city infrastructure system. Scaling the images in this way affords for the buildings and monuments to be individuated and categorised within the areas in need of regeneration. The following typo-morphological analysis are described for each area of intervention.

\subsection{Typo-morphologic analysis}

This paper presents the typo-morphological analysis conducted on one of the key eight selected areas in Aberdeen, including the related discussions concerning the data and information collected.

\section{Castlegate:}




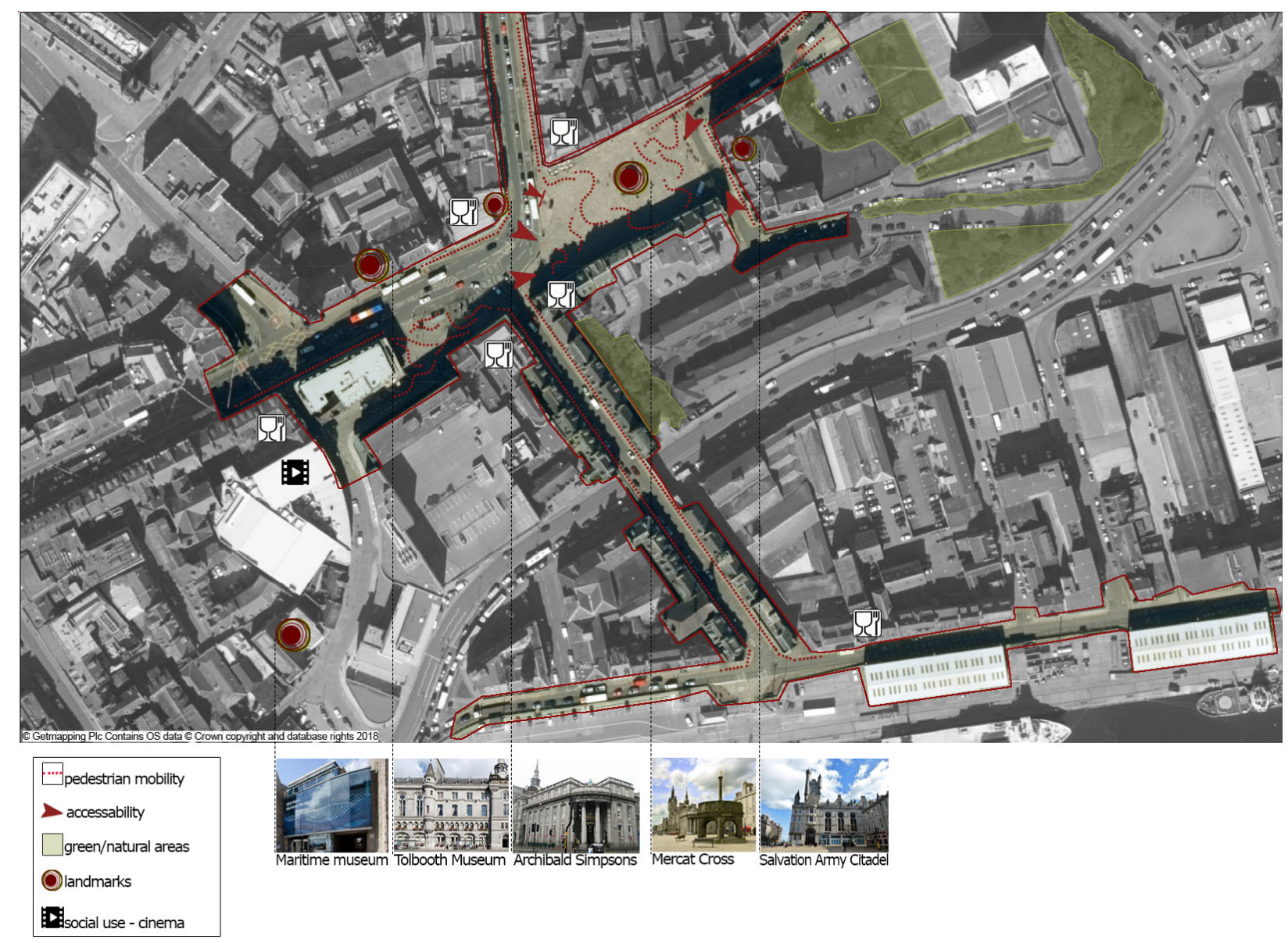

Fig.4: Castlegate typological map 


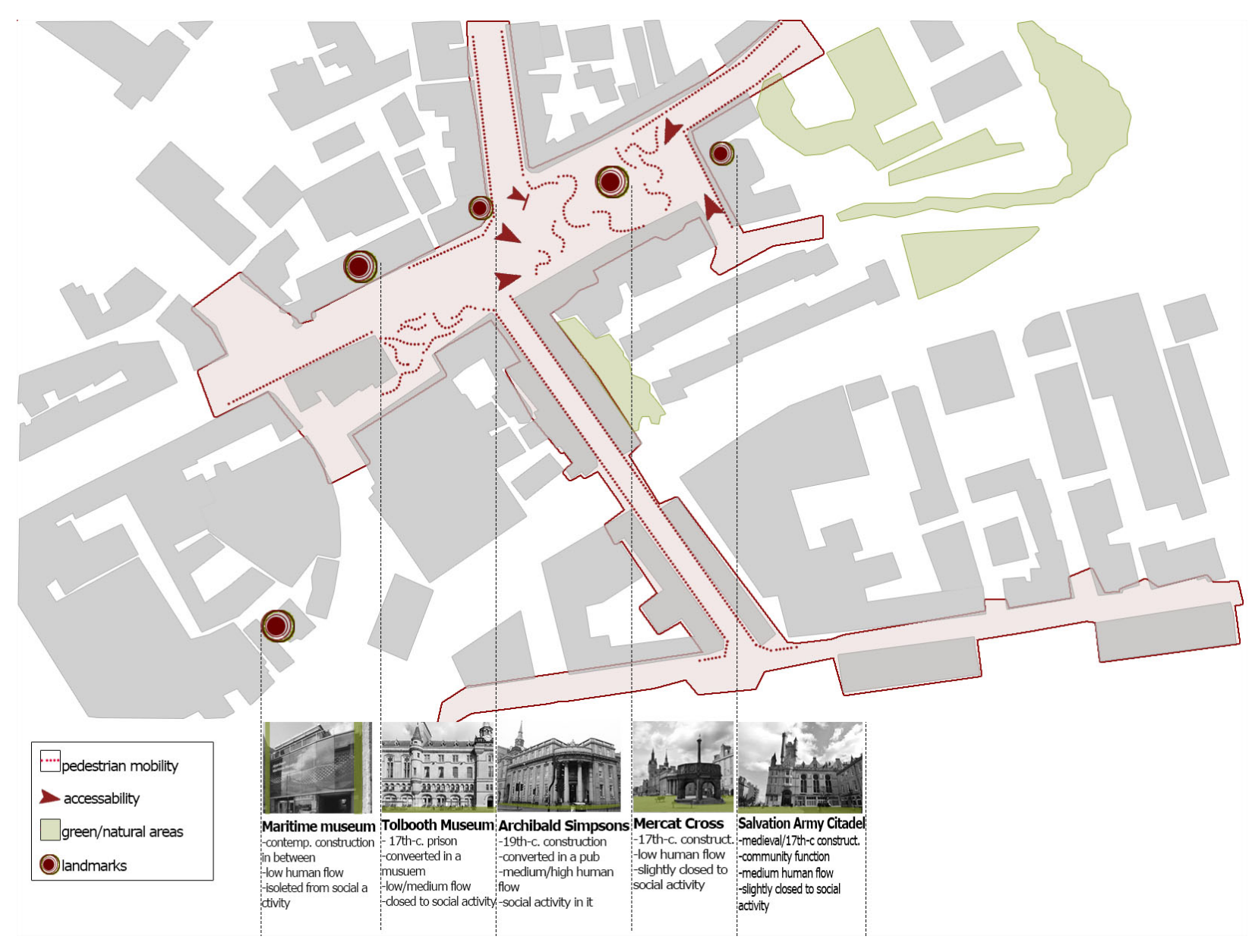

Fig.5: Castlegate morphological map

Castlegate is situated near to the headland of Castlehill in a dense and historical area. It is the only public open space presented there but the accessibility is limited by the intense traffic of Union and King Street.

The accesses on the east end are less utilised and not directly connected with other parts of the city. Particularly Justice Street, which descends on the north side of the square, leads down to a traffic junction, node of four main roads.

In terms of urban morphology, the orientations of the buildings and their configurations seem to converge on Castlegate space which becomes the focal point of the city space. It is evident that a predominant direction of the flows on the east-west axis and a lack of connectivity in the 
perpendicular direction which would lead to the harbour. The presence of green spaces is not evident apart from some residual areas on the east side of the hill. The built environment within Castlegate is an overlaying of different periods particularly on the harbour areas included Marischal Street, which appears as transitional space with not particular attractive character or social function.

Some main buildings may be distinguished and categorised as landmarks for their specific historical meaning or social use. Particularly from the typological analysis it emerges that Tolbooth, Archibald Simpson and Salvation Army Citadel buildings have significant architectural and historical values, which are not highlighted through the open and in-between spaces of area. The lack of pedestrian and public confluences, particularly from Marischal, Castle and King Street pulls the focus on other directions to the disadvantage of urban permanencies as a sign of the city identity.

\subsection{Rhythm analysis - city centre}




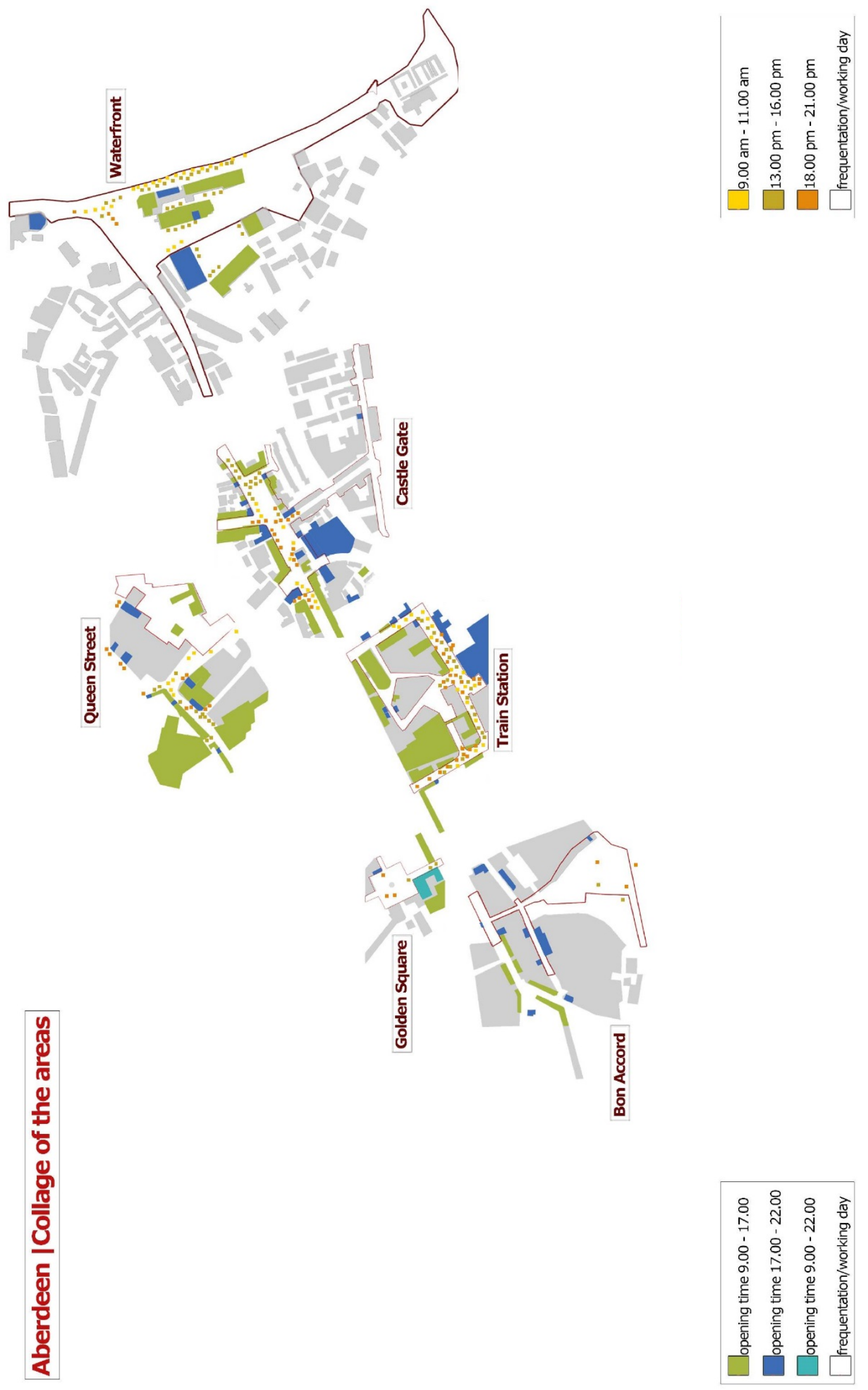

Fig.6: Rhythm of Aberdeen areas 
Castlegate

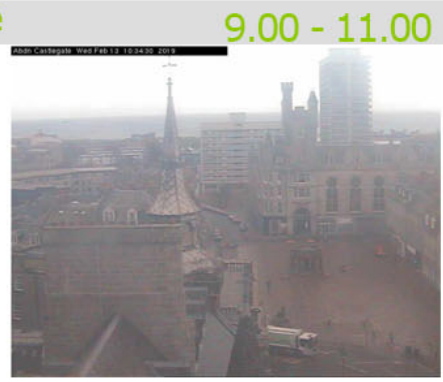

Waterfiont

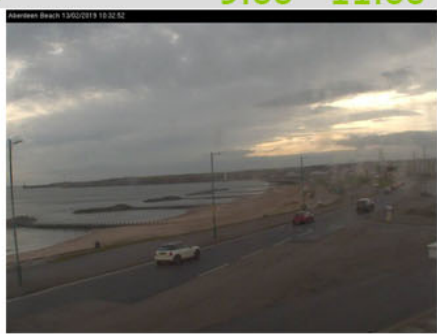

$9.00-11.00$

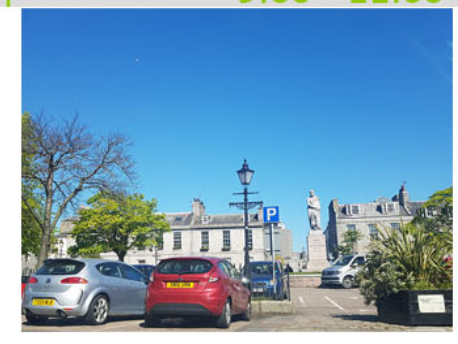

Golden Square

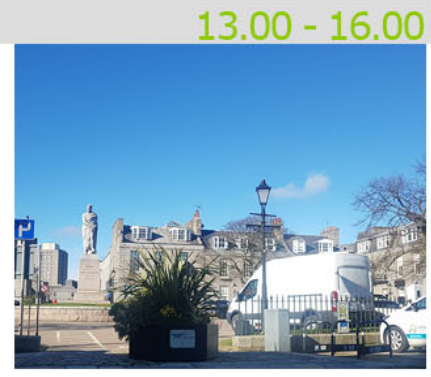

Bon Accord area
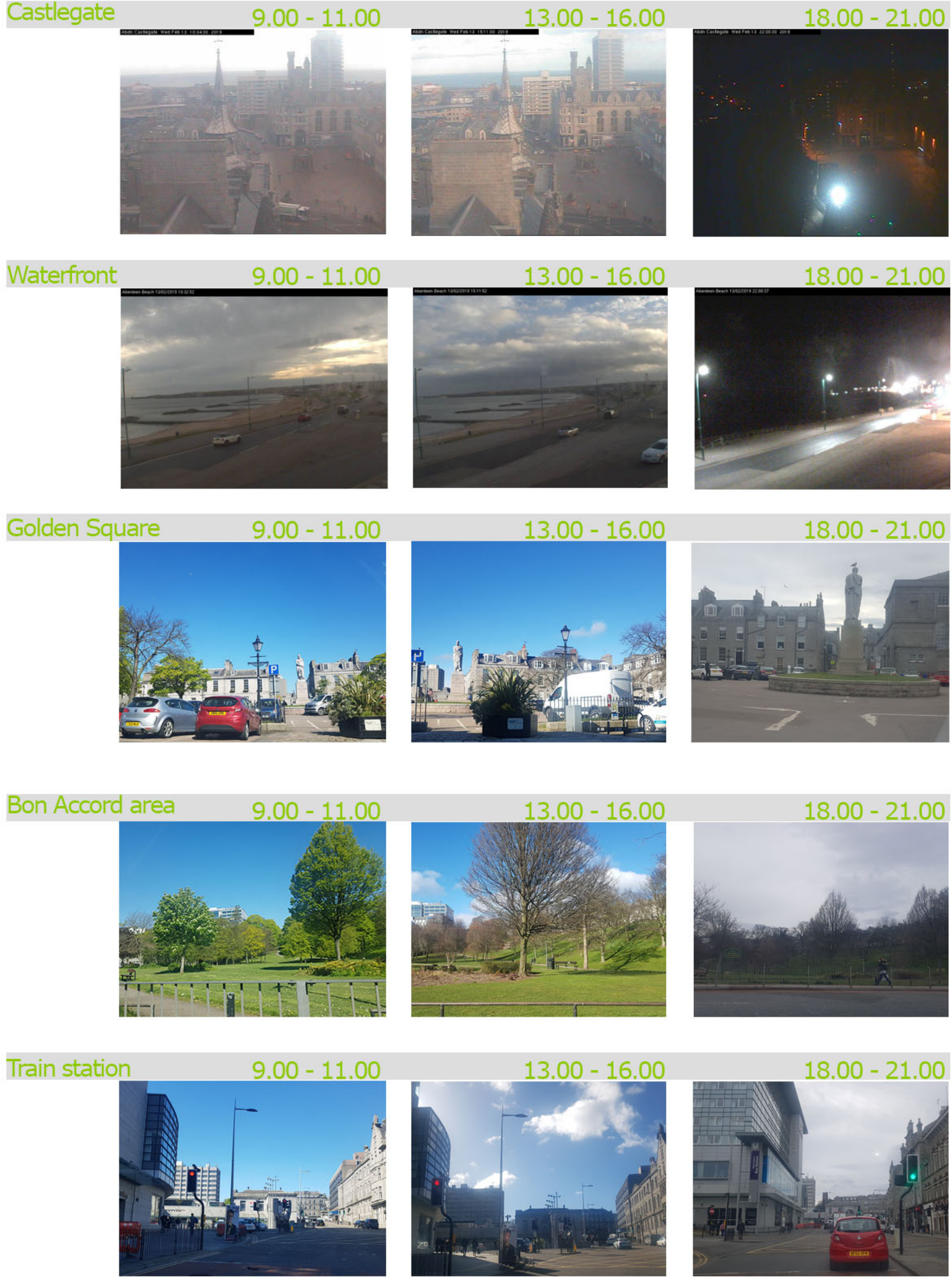


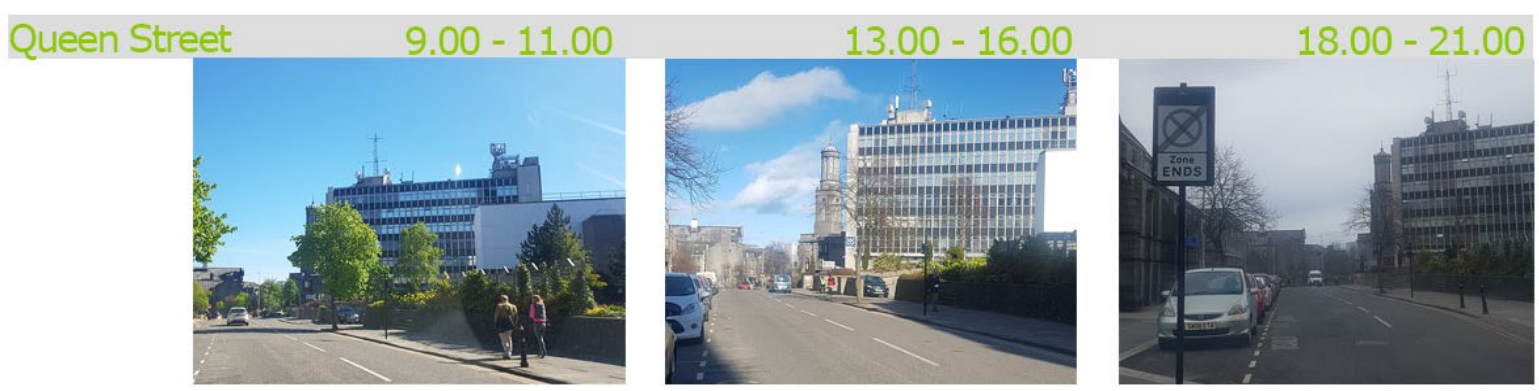

Fig.7: Example of frequentation time. Photos of the areas, rhythm at different times.

The data collected with the rhythm analysis are crucial because they represent the social practices and the characters of the area. The map (fig. 6) represents two different experiences both spatial and temporal.

Firstly, the opening times of activities divided in two categories, $9.00 \mathrm{am}$ to $5.00 \mathrm{pm}$ and $5.00 \mathrm{pm}$ to $22.00 \mathrm{pm}$, create a patchwork of the typical places of congregation within a specific frame of time. This is particularly useful in understanding the flow of users, the new or changing life styles and consumptions and to propose bespoke and new activities related with that frame of time during the design proposals.

Secondly, with help of photographs and urban webcams images, the pixelated diagrams create an image of the intensity of users' frequentations of the area during a working day. The data were collected in morning, afternoon and nights. The map shows an overage of the frequentations.

From the opening time of activities, it is possible to notice as the day activities are more predominant than during evenings. Particularly they are distributed along Union Street while the few activities are disappearing at the edge of the city centre, such as on the Queen Street area as well as the area of the waterfront. This represents a sort of fragmentation on the map 
and suggests that an increment of activities, or a better balance between day and night could be a way for regenerating the spaces.

From the frequentations map it is possible to notice that during a working day some areas are not experienced, particularly both parks and the waterfront for their location far from the city centre and core of the main activities. The Beach Boulevard however seems to be highly frequented and this can be due also to the presence of supermarkets and shops.

Castlegate, Golden Square, Bon Accord and Queen Street areas appeared as transient spaces with no activities able to generate social places of staying. The train station area is generally crowded, even in a weekend day, and this is due to a combination of functions and streets infrastructures. The issue of being an unsolved urban area seems to be related to pedestrian flows relegated to narrow spaces and the closed pedestrian connections after the day opening times.

The rhythm of the waterfront appears to be sharply defined by the seasons and the weather. Particularly, all activities are mainly focused during the day and rarely they are prolonged over the night time.

The city wide rhythm map enabled to raise various consideration even in terms of projects. This is due to its essence of being both a description of the territory and a description of what is missing and should be implemented. The map also suggests that possible regenerations can be done through micro-local temporal actions, such as the opening times, and through selecting specific functions for the area. 


\subsection{Mental map}

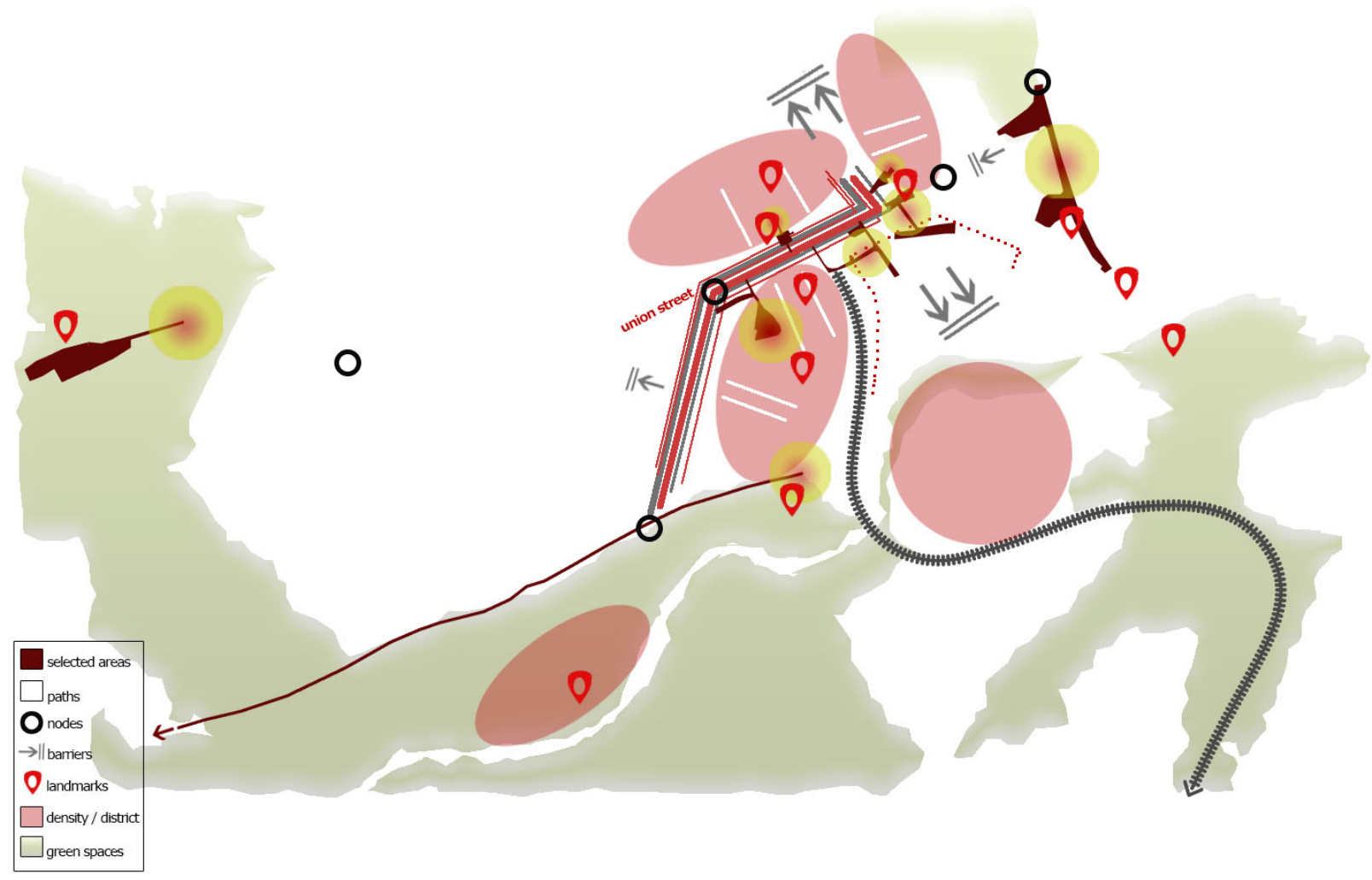

Fig.8: Aberdeen mental map

The mental map (fig. 8) was graphically summarised collecting data during the meetings with local authorities.

Firstly, the abundant greenery around Aberdeen city characterises its particular natural aspect but it is also visible as it is almost completely missing within the city centre and the west settlements.

Holburn, Union and King Street are evidenced as a unique spine which divides the main city areas, marked with red circled patterns. Furthermore, the spine often generates barriers in crossing the urban spaces, making difficult links between main roads and urban paths. 
Various landmarks are present within the city but they tend to disappear visually on urban scale maps, this probably being due to congestion of the built environment. By using a mental diagram it is more evident the quantity of historical and social landmarks and their potentiality given a regeneration's plan. Particularly they seem also strategically located within the central areas along Union Street and aligned in the surrounding areas such as the waterfront and the parks. This potentially suggests a crossing (Union Street areas) and linear geometry (waterfront and parks) for setting urban design projects.

\section{Categorisation of Aberdeen abandoned areas}

By adopting these types of analysis, it was possible to gather objective data on the areas taken in examination, which have supported the following considerations regarding the nature of these spaces and their level of abandonment. Particularly what emerged is a general level of isolation and lack of connectivity with the social places within the city as thoroughly described for each site hereunder:

1. Castlegate should be one of the main squares in the city but currently it is isolated and not connected with the other urban environments and this makes it fall in the category of fragmented voids. Analysing also the potentiality of its transversal connectivity with the harbour waterfront, what emerged is a system of underused buildings including those one with more industrial features. In conclusion the entire area may be described as both a fragmented void with punctual empty spaces which potentially can contribute to reinvigorate the area if reused.

2. The Aberdeen waterfront presents many fragmented voids around its line, particularly those one underneath within the esplanade ramps' creases. Yet some green spaces are underused and their being encircled with roads reinforce this connotation. The presence of unrelated buildings 
closed to each other but mainly the presence of massive supermarket and carparks, highlight also a non-place connotation.

3. Golden Square, as noticed during the analysis phase, is a roundabout serving carpark spaces. The only function of carpark attributable to the area lies mainly in the non-place category.

4. Bon Accord garden and its surrounding area represents an urban green fragmented void within the city. Its isolation does not allow a whole use of the park by citizens and the presence of abandoned buildings within the park and the area such as the brick garden and Bon Accord bath fall within the empty space category.

5. The train station area, seen as a system of different buildings, streets, shopping malls, market and pedestrian areas, is a complex overlap of disaggregated factors which do not dialogue with each other. This sort of urban entropy together with elements out of scale, such as Trinity centre, the market and the shopping mall attached to the station, generate a certain level of nonplace feeling.

6. Queen Street, as emerged from the morphological analysis, represents a fragmented void inbetween the city and its main landmarks. Its function of connection is limited and the absence of a specific urban and social purpose make it fall also within the category of non-place.

\subsection{Table taxonomy of the areas}

The beauty of a city, ergo the concept of harmony suggests that a certain level of density and intensity of urban relations, but also the rhythm such as time, tempo and infrastructures, defines the quality of a place.

Following the classification and the identification of non-places, empty places and fragmented voids within the areas taken in examination, it is helpful to quantify those spaces to better 
understand their roles within the city and thus what strategies of intervention are more suitable to address the issues.

In this regard, according with the common urban site ratio used to calculate the index of built areas, an indicator data-set is proposed, considering the relationship between the sum of the abandoned areas and the area upon which they are situated. As described in section 2, it is possible to define if a space is a non-place, a fragmented urban void or an empty space. An abandoned space is generally within a larger area considered by the development plans or masterplan issued by local authorities. Once one subcategory is recognised, it will be possible to determine its area in square meters. If the area presents more than one subcategory, then the sum of the abandoned areas will be considered. The result can be then divided by the total square meters of the area considered in the local development plan or masterplan. For instance, in the 2015 Aberdeen city masterplan, the Castlegate area included Marischal Street, part of Regent Quay and part of King Street. Castlegate Square can be defined an urban fragmented void because is rarely crossed by citizens and is not used as a collective and social space. Along Marischal Street and Regent Quay are currently present empty buildings which fall into the category of empty spaces. The sum of the square meters of urban fragmented voids (Castlegate Square) and the square meters of empty spaces (uninhabited buildings) will be divided by total area considered by the local authorities.

This simple spatial calculation enables to measure and compare the quantity but also the quality of the urban and social spaces selected around Aberdeen city.

The result of this formula may be defined as an index value no greater than 1 which defines the urban character of areas in need of regeneration. The following table shows the data collected through the urban analysis and the categories of the spaces related with the areas within Aberdeen city. 


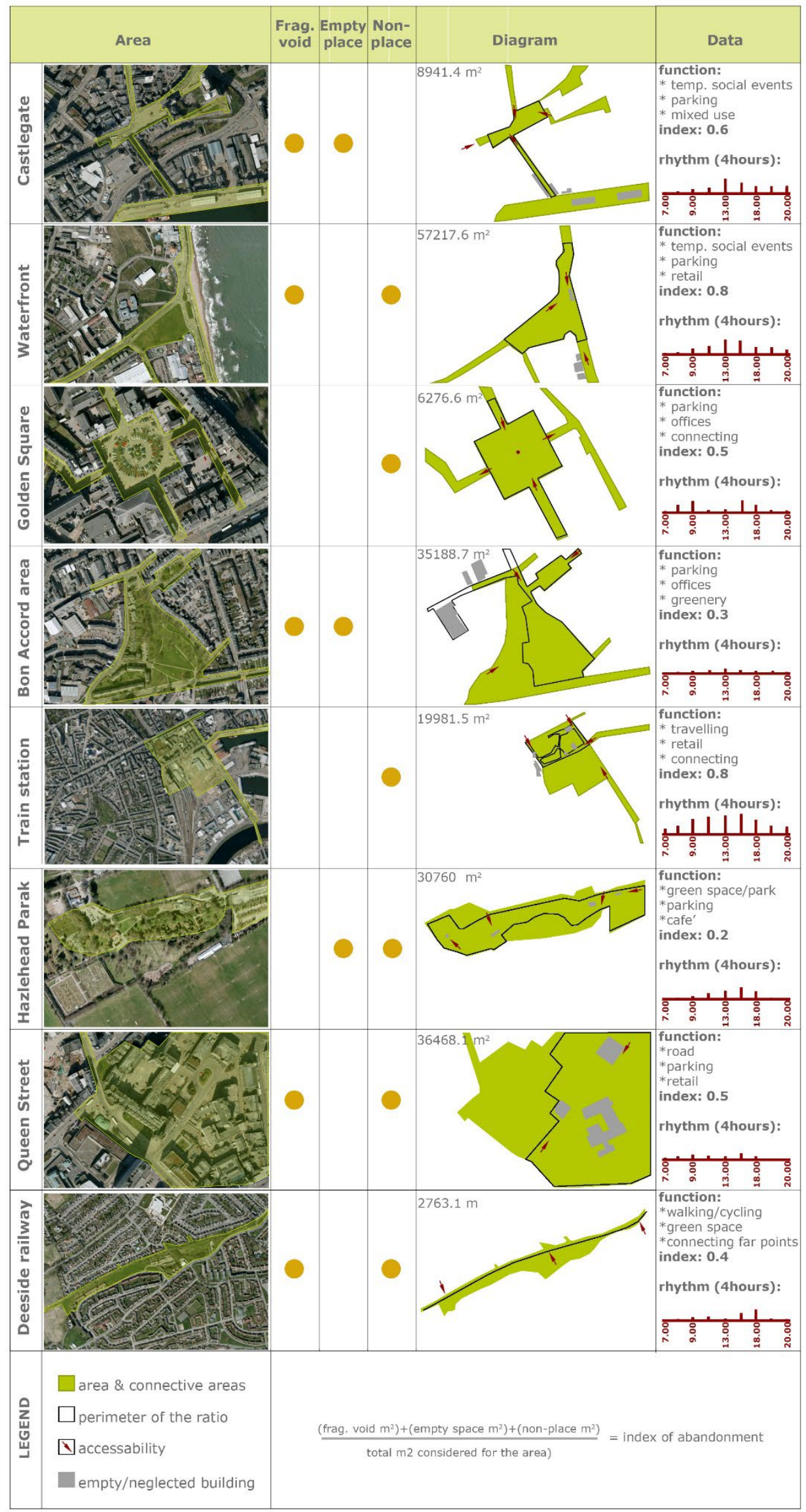


Table. 1: Taxonomy of abandoned spaces in Aberdeen

\section{Closing remarks and conclusions}

This research analysed areas across Aberdeen, highlighting the urban and architectural issues that generate phenomena of urban and architectural abandonment. Furthermore, the data collected and results have been categorised within a table in accordance to their nature of being fragmented void, empty place or non-place.

Alternative urban analysis enabled to deeply understand the areas from different aspects. This was particularly suitable for recognising and studying the three categories of contemporary abandonment phenomenon, fragmented void, empty place or non-place. Specifically, the frequentation map, the urban rhythmicity and mental map highlighted how the spaces are used

or unused, pointing objectively out the weaknesses and potentialities of these urban environments.

This research has taken a design and context-based approach to the identification of abandoned and under-utilised urban spaces, and provides an innovative methodology to aid the planning and design teams. This complements other recent reported work (e.g. Aigwi et al 2019), which sought to prioritise spaces in reference to stakeholder groups, thus assisting the decision forming process.

These selected urban analyses have also proven to be analytically effective for identifying and quantifying the concepts of urban abandonment introduced in the preceding chapters. 


\section{References}

Aigwi, I.E., Egbelakin, T., Ingham, J.,Phipps, R., Rotimi, J. and O. Filippova (2019) A performance-based framework to prioritise underutilised historical buildings for adaptive reuse interventions in New Zealand, Sustainable Cities and Society, (48) July.

Auge', M., 1995. Non-places: introduction to an anthropology of supermodernity. London: Verso.

Barresi, A., Pultrone, G., 2009. The contribution of morphological analysis in the rehabilitation of peripheries. Atti del Convegno Nazionale INU "Quante periferie? Quali politiche di governo del territorio". 22-23 March 2007. Planum.

Calaprice, A., ed. 2000. The Expanded Quotable Einstein. New Jersey, United States: Princeton University Press.

Carriello, A., Ferorelli, R., 2014. Riuso del paesaggio in abbandono. Domus. [online] Available from:

https://www.domusweb.it/it/opinion/2014/01/09/riuso_del_paesaggio_in_abbandono.html [Accessed 2017]

Corsaro, E., 2010. Dismissione: da anomalia a regola. Caratteri, criticità e ruoli delle aree industriali dismesse per Adriapolis: teoria per un' agenda strategica di indirizzo. $\mathrm{PhD}$ thesis, Università degli studi di Camerino - Facoltà di Architettura sede di Ascoli Piceno (IT). 
Dell'aguzzo, M., 2013. Urbanizzazione in Europa: Una diagnosi comparativa. [online] Master thesis, Università degli Studi dell'Aquila. Available from: http://www.planeco.org/staff/romano/web-cORSI/Tesi_Laurea/dell_aguzzo.pdf

Emerson, T., 2014. Glasgow Atlas, Studio Tom Emerson. Glasgow

Formato, E., Fatigati, L., Gallucci, P., 2001. Tipi edilizi e forma della città. Naples: ed. Fiorentino NT.

Gregotti, V., 1966. Il territorio dell'architettura. Milano: Feltrinelli.

Hetherington, K. and Smith, R.J., 2013. Urban Rhythms: Mobilities, space and interaction in the contemporary city. The Sociological Review. [online] (61)1 (supplement)

Lefebrve, H., 2004. Rhythmanalysis. Space, Time and Everyday life. New York: Continuum.

Lynch, K.A., 1960. The Image of the City. MIT Press.

Mareggi, M., 2017. The over-familiar landscape that escapes to the absent-minded gaze, The Journal of Public Space. [online] (2)1

Maretto, M., 2013. Saverio Muratori: towards a morphological school of urban design. Urban morphology. [online] (17)2 
Misırlısoy, D. and K. Günce (2016) Adaptive reuse strategies for heritage buildings: A holistic approach, Sustainable Cities and Society, (26) 91-98

Muratori, S., 1967. Civilta e territorio. Rome: Centro studi di storia urbanistica.

Ritzer, G., 2004. The Globalization of Nothing. Thousand Oaks, CA and London: Pine Forge Press.

Rossi, A. and Eisenman, P., 1982. The architecture of the city. American ed. revised by Aldo Rossi and Peter Eisenman. ed. London: Graham Foundation for Advanced Studies in the Fine Arts.

Sema Uzunoglu, S. andUZUNOGLU, K., 2011. The application of formal perception of gestalt in architectural education. Elsevier Ltd. pp. 994 